\title{
Environmental conflicts and women's vulnerability in Africa
}

Edwin C. Perry, Cheryl Potgieter and Urmilla Bob ${ }^{*}$

\begin{abstract}
This article examines environmental conflicts and women's vulnerability in Africa. Environmental resources are critical to poor women's productive and reproductive lives in Africa. Environmental resources diversify livelihoods and are key to the survival strategies women adopt. Environmental conflicts are of concern in several parts of Africa and they have gendered impacts that need to be considered. This article focuses on two main aspects. The first examines the linkages between environmental conflicts, women's vulnerability and gender-based violence. The second considers environmental conflicts, access to resources and women's vulnerability. In particular, the focus is on the way
\end{abstract}

* Dr Edwin C. Perry is a research consultant and completed his Doctoral studies at the University of KwaZulu-Natal, Durban.

Prof Cheryl Potgieter is the Dean of Research at the University of KwaZulu-Natal.

Prof Urmilla Bob is Associate Professor in the Discipline of Geography, School of Environmental Sciences at the University of KwaZulu-Natal. 


\section{Edwin C. Perry, Cheryl Potgieter and Urmilla Bob}

in which conflicts restrict women's access to and control of environmental resources. Additionally, the impacts of environmental degradation which tend to characterise environmental conflicts are considered. The article also briefly discusses women's responses and adaptation strategies to the challenges they confront in relation to environmental conflicts.

\section{Introduction}

Pillay (2009:91), in an examination of Liberia, asserts that conflict is highly gendered and that men and women experience conflict differently. Veuthey and Gerber (2009), focusing on logging conflicts in Southern Cameroon, assert that although there is more research recently on women and the environment in terms of development impacts, a focus on gender in resource conflicts remains neglected. This article seeks to understand the relationships between women, violence and environmental conflicts, especially in Africa. In particular, two aspects which are the main impacts that women experience in relation to environmental conflicts are critically examined. The first is in relation to genderbased violence since environmental conflicts increase women's vulnerability significantly. The second is a focus on environmental conflicts reducing the quantity and quality of environmental resources available to women. Access to environmental resources impacts directly on women (and their households) achieving sustainable livelihoods and attaining food security.

\section{Environmental conflicts, women's vulnerability and gender-based violence}

For the purposes of this article, the World Health Organisation's (2002:5) definition of violence is used:

The intentional use of physical force or power, threatened or actual, against oneself, another person, or against a group or community, that either results in or has a high likelihood of resulting in injury, death, psychological harm, maldevelopment or deprivation. 


\section{Environmental conflicts and women's vulnerability in Africa}

Additionally, the United Nations (1995:121) defines violence against women as:

Any act of gender-based violence that is likely to result in physical, sexual or psychological harm or suffering to women, including threats of such acts, coercion or arbitrary deprivation of liberty, whether occurring in public or private life.

This definition allows for the critical examination of what violence is (or is perceived to be), the nature and forms of violations against women, what impacts these violations have on women, the context in which these violations take place (spatial dimensions) as well as the power dynamics associated with violence against women. According to Morrell (2002:37), violence and violation in society 'is best understood using a gender perspective' since 'a gendered analysis allows an examination of violence in terms beyond victim and perpetrator'. Violence against females is undoubtedly one of the most disconcerting aspects of a society that promotes hierarchical power relationships on the basis of class, race, ethnicity and gender as well as other divisions.

Undoubtedly, environmental conflicts often breed a culture of violence and the most vulnerable are more likely to be victimised. The concept of vulnerability is important with regard to conceptualising both poverty and violence in society. It is imperative that poverty is viewed not only as being poor but also as linked to having higher levels of risk of becoming poor or poorer, especially in times of change and stress/shocks. The ability to withstand shocks and stressors is often linked to the assets available to a particular individual or household. Chambers and Conway (1992:9) state:

A livelihood comprises the capabilities, assets and activities required for a means of living. A livelihood is sustainable when it can cope with and recover from stresses and shocks and maintain or enhance its capabilities and assets both now and in the future, while not undermining the natural resource base. 


\section{Edwin C. Perry, Cheryl Potgieter and Urmilla Bob}

Assets may take a variety of forms: stores of financial wealth; physical possessions/ property; productive resources (such as land and businesses), human assets such as labour and education; and social capital.

Most gender-based violence is characterised by the assertion of power and control over females. Those who use violence may bully, intimidate, verbally insult, sexually coerce, or physically harm others into submission (Nadesan 2000 illustrates these in the Asian context) and these forms of violence characterise environmental conflicts. Perry (2002) and Rude (1999) state that it is best to view violence in the context of a continuum where physical violence in the overt sense of physical assaults, shootings, mutilation and so on, is at one end. They indicate that closely related to this is threatened violence - either verbally expressed or denoted by specific actions. Although no physical harm to a person actually results, it is important to note that this can be deemed to be abuse and harassment (especially emotional and psychological abuse) which in itself are forms of violence. There are several environmental conflict (or conflicts in general) situations that imply that violence is possible and has a gendered component. For example, more men carry weapons and this implies that men are more likely to be the perpetrators of violence and women the victims. Furthermore, men tend to have the power (specifically money and position) to organise and plan violent attacks while women generally do not. This analysis underscores the contention that although much of the debate on violence focuses on physical violence and sexual violence, it is imperative that there is also a need to understand the dynamics of dominance and hierarchy in its various forms in society from one end of the continuum to the other. It is this that permits a more nuanced comprehension of women's vulnerability during periods of environmental conflicts.

Women's fear of crime and violence is much greater than that of men in any situation. This can be attributed to the pervasiveness of patriarchy in society. In marginalised communities, abject poverty, severe overcrowding, desperate land hunger and insecure tenure status, a breakdown of traditional familial and community structures as well as 'dumping' people from different backgrounds together heighten vulnerability for most women. The gendered division of labour in most countries also makes women the first to suffer from the direct 


\section{Environmental conflicts and women's vulnerability in Africa}

and indirect depredations wrought by violent conflict (Brittain 2003, cited in Barnett and Adger 2007:644). Environmental conflicts are no exception.

The main forms of violence against women that are experienced during times of environmental conflicts relate (but are not limited) to theft, physical abuse and assault, psychological abuse, sexual harassment and sexual assault (including rape), reproduction violence which can be linked to sexual violence (such as unwanted pregnancies, unsafe abortion, complications from high risk pregnancies and sexually transmitted diseases) and exploitation such as overpricing of goods and services. Sexual harassment and sexual assault are deemed to be the most horrific among the various forms of violence. Pain (1991:417) argues that sexual violence is unique in its nature as a crime and that rape in particular is one of the most traumatic of crimes. These crimes can have long lasting effects and can add to women's fear, which is considered as one of the foundations of patriarchal control. Mackenzie (2009:1) states that the emphasis on 'immediate' and 'hard' security issues over 'everyday politics' has meant that rape as a tactic of war in Sierra Leone and children born as a result of rape are two issues that have largely been pushed to the margins of conflict, development and security studies. This is the case in most environmental conflict situations where rape and other forms of sexual violence are increasingly used as a weapon of war.

Garcia-Moreno (1998) asserts that most survivors suffer from post-traumatic stress disorders (psychological, emotional and spiritual damage) as a result of violence and the fear of violence. Furthermore, for the majority of women the persistent insults, abuse, confinement, harassment and deprivation of financial and physical resources may prove more harmful than physical attacks and result in women living in a permanent state of fear and sub-standard mental and physical health (Garcia-Moreno 1998). Linn et al. (1996) indicate that the consequences of disclosure of being violated, especially in relation to sexual victimisation, may be disastrous and can include rejection, blame, 'social death' and even further violence.

The interest in violence against women has become marked in the past several years. Women's movements, service providers, non-governmental organisations 


\section{Edwin C. Perry, Cheryl Potgieter and Urmilla Bob}

(NGOs), researchers and development practitioners have begun to underscore the need to examine issues pertaining to women and violence linked to conflicts. Of particular interest is the way in which violence and/or the fear of violence contravene women's rights, constrain women's ability to participate meaningfully in and benefit from development and transformation processes, and impact on their quality of life. Issues concerning women and violence have been overlooked when broad-based social, economic and political planning has taken place in dealing with conflicts. Violence and/or the threat of violence can contribute significantly to maintaining gendered relations of subordination. Conflicts contribute significantly to reinforcing power and control in different spheres of our society including homes, communities, educational institutions, workplaces as well as social places. These power relations are highly gendered and women tend to bear the brunt of impacts in the productive and reproductive spheres.

Violence against females takes place more frequently during periods of conflict, especially when physical violence characterises the type of conflict experienced and when the conflict occurs in societies that tend to be patriarchal. Women's vulnerability increases significantly during periods of violence, and environmental conflicts are no exception. This aspect is particularly important given that environmental conflicts often result in displacement, migration and/ or refugees.

The spatial dimensions related to women and environmental conflicts are important to consider. The imposition of gendered constraints on the use of space and environmental resources is a critical aspect that impacts on women's lives during periods of conflict. Women rely heavily on the natural resource base and are most impacted by environmental conflicts that further degrade the natural resource base, limit or deny access to resources and create insecure spaces for women. The latter is also linked to the social construction of space into 'safe' and 'unsafe' areas, and the social control of women's spaces.

Environmental conflicts often result in increased places of high risk for women. Often, security personnel's inability to protect resources and innocent people also exacerbates the situation. For example, Simiyu (2008:30) shows the security 


\section{Environmental conflicts and women's vulnerability in Africa}

personnel's inability to wipe out the militia involved in resource conflicts in Western Kenya. In fact, the security personnel adopted the strategy of turning on residents for withholding information and treated all young men as suspected militia fighters. Simiyu (2008:31) states that according to media reports and local human rights organisations, as well as the Kenya National Commission on Human Rights (KNCHR), this change in tactics on the part of the police resulted in widespread human rights violations. They allegedly tortured and killed innocent suspects, destroyed houses in the settlement scheme where militiamen were suspected to be in hiding, looted property, extorted money from the residents, and sexually abused women (KNCHR 2008, cited in Simiyu 2008:31). The forests became a haven for the perpetrators of the violence. An example is that on the $4^{\text {th }}$ of April 2008 the police rescued three women who had been raped and tortured by a gang in the forest after being abducted (Daily Nation, 6 April 2008, cited in Simiyu 2008:36).

While studies have demonstrated that gender-based violence is a characteristic of environmental conflicts (see for example Brocklesby and Hinshelwood 2001; Fred-Mensah 2003; Ogra 2008; Veuthey and Gerber 2009), there are very little data available on the actual and perceived spatial distribution and understanding of gender-based violence and vulnerability related to environmental conflicts. The sources and meanings of how women themselves perceive the environment and the conflict are critical to understand gender and violence. The main sources of information about women's vulnerability in environmental conflict situations are based primarily on official (usually police) statistics, victim surveys and a series of estimates by organisations working with survivors of violence. It is important to note that there is consensus that in most cases violence against women is not reported to official sources, including the police. Furthermore, victim surveys and information from the survivors of violence tend to be limited to specific case studies and/or anecdotal experiences. Despite their limitations, these studies provide valuable information about the plight of women and key issues in relation to a gendered analysis of environmental conflicts. However, there have been numerous calls to provide more substantive information and rigorous research about the nature, scope and dimensions of the problem. 


\section{Edwin C. Perry, Cheryl Potgieter and Urmilla Bob}

There are also political consequences in relation to women's increased vulnerability. The earlier discussion illustrated how fear of victimisation restricts women's lives and causes distress. Additionally, particularly when conflicts result in extreme violence, vulnerable community members often retreat from public spaces. Given the patriarchal nature of societies, women's participation in the public sphere is generally limited in any event. This retreat often results in women's experiences and issues not being raised when the impacts of the environmental conflict/s are being discussed and intervention strategies are being developed.

\section{Environmental conflicts, access to resources and women's vulnerability}

There is acceptance that poverty and environmental degradation (an important aspect of several types of environmental conflicts) have disproportionate impacts on African women (especially those who reside in rural areas). The feminisation of poverty is well documented. However, there is a dearth of studies that examine the feminisation of environmental conflicts in relation to the disproportionate burdens and increased vulnerability women face as a result of environmental conflicts. Their vulnerability is also directly linked to the fact that although women constitute more than half of the population and provide the majority of

the food supply in developing countries, they have limited access, ownership and co-ownership to land and natural resources. Specifically, Mkhabela (2006:67), examining land conflicts in Swaziland, states that women's contribution to labour and management in food production has been put between 60 and $80 \%$. Therefore, environmental conflicts have a direct impact on their lives, especially in poor communities. Pillay (2009:98) illustrates that in the case of the Liberian violence, women were less concerned about redress and reparations for sexual violence but more concerned about the loss of their livelihoods as well as their ability to access resources such as safe water and services such as education and health care.

In the context of rural Africa, the multiple burdens on women are particularly acute due to women's economic dependence on men, reinforced by cultural 


\section{Environmental conflicts and women's vulnerability in Africa}

traditions and religious practices that dictate women's relationships and roles in societies as well as the relationships to resources, especially land. Power relations from the household to the highest public level impede women's ability to lead productive and fulfilling lives. Extensive research shows that in comparison with men, women are generally at a disadvantage in terms of control and access to resources, including land (Agarwal 1996, focusing on India; Cross and Hornby 2002, focusing on South Africa; Fred-Mensah 2003, focusing on the Ghana-Togo border; Rao 2006, focusing on India). Women are less likely to reallocate the few resources they do command. Yet, women are key environmental managers and consumers. Their vast knowledge about the environmental resources they use is key to sustainable development. Sustainable livelihoods have direct links to women and their access to natural resources such as water, firewood, medicinal plants, wild foods and agricultural land. Environmental conflicts often resulted in restricted access to or degradation of these vital resources.

Women are also important traders of environmental resources in rural areas. Competition over resources and pricing can sometimes create conflicts. For example, Bennett et al. (2001:371) demonstrate the gendered nature of tropical fishery conflicts over price in Ghana. They show that while the fishermen claim that women traders did not offer a fair price for the catch, the women contend that the fishermen were unrealistic about what the catch is worth. Bennett et al. (2001:371) further state:

Although at first this appears to be market competition rather than conflict, the women traders reported that the fishermen often abscond to other villages to avoid credit repayments. At this point what was competition appears to become a conflict as the rules are broken.

Human-wildlife conflicts are a major source of environmental conflicts in Africa, particularly Sub-Saharan Africa where protected areas are important for the economy and nature conservation efforts. However, the history of conservation areas in Africa has generally been one of dispossession and marginalisation of local communities. Several conflicts characterise Africa's protected areas and relate to loss of life or physical harm to humans by wildlife attacks, crop damage, 


\section{Edwin C. Perry, Cheryl Potgieter and Urmilla Bob}

stock predation, property damage, natural habitat destruction, contestation over the distribution of levies/fees, poaching, etc. Ogra (2008:1408) illustrates the gendered nature of human-wildlife conflicts in protected areas in India which are also relevant to Africa. She found that costs of human-wildlife conflicts included decreased food security, changes to workload, decreased physical and psychological well-being, economic hardship, and at times an increase in illegal or dangerous activities. The research also showed that women bore a disproportionate burden of these effects because of relationships between gendered uses of space, work, status, and identity. Ogra (2008:1408) asserts that it is important to address both visible and hidden costs of human-wildlife conflicts for members of park communities, and specifically calls for increased gender-sensitivity in human-wildlife conflict research.

Environmental conflicts can also result in environmental degradation that can have an impact on the health and well-being of people. Women in particular could be differently impacted than men. For example, air pollution has often been linked to weakening of women's reproductive health status.

Smiley and Roux (2005) illustrate that while individual people experience stress due to personal events (deaths, marriages, job changes), communities of people also experience daily stress due to features in their neighbourhoods (such as crime and environmental changes such as floods). They assert that these environmental stressors have the potential to impact entire communities, and yet are difficult to define and measure. Several studies also illustrate that environmental damage can have particular significance for the poor (Dasgupta et al. 2005). Brocklesby and Hinshelwood (2001) in particular demonstrate that a common perception of the poor is that environmental quality is an important determinant of their health, earning capacity, security, energy supplies, and housing quality. Kuo and Sullivan (2001) illustrate the power of the physical environment to influence human aggression. Also, environmental conflicts often result in physical deterioration which leads to potential offenders viewing the areas and inhabitants affected as potential targets. Furthermore, the impacts and concerns are highly gendered. Therefore, the cost of environmental conflicts for the have-nots (who are often poor women and children) is greater, given restricted access to resources and opportunities as well as fewer available 


\section{Environmental conflicts and women's vulnerability in Africa}

mechanisms - such as the ability to move, or resources to increase protection to cushion the effects of being victimised.

The actual costs of environmental conflicts on women are highly complex given the impacts on productivity levels (specifically since women are usually involved in the informal economy) and costs associated with what Frank (2005:33) refers to as 'victimless' crimes such as gambling, drug crimes, and prostitution. Furthermore, 'hidden crimes' such as corruption, fraud and sexual offences cannot be easily quantified as there are no methodologies that produce reliable estimates. Thus, examining the impacts of environmental conflicts and costing these in society are difficult to achieve.

\section{Women's responses and adaptation strategies}

Various factors affect who is impacted by environmental conflicts, how they are impacted and how they respond. These factors include positions related to gender, class, age, ethnicity, race, location, etc. which influence significantly women's experiences of and reaction to environmental conflicts and/or the perceived threat of these conflicts. Several authors (Bogale et al. 2006; Brocklesby and Hinshelwood 2001; Dasgupta et al. 2005; Ogra 2008; Smiley and Roux 2005) specifically highlight the links between poverty, vulnerability and environmental conflicts. Additionally, women and children are the poorest of the poor globally. Thus, women are particularly vulnerable in contexts, especially in marginalised areas where insecurity is relatively high and people often lack resources and opportunities to adequately cope with impacts that emerge from environmental conflicts. In addition to the strain that poverty places on households, it also impairs the ability of certain members of a household (such as women, the elderly and children) to leave a violent household or community. They are bound by economic dependence, and usually also by cultural ties.

Women are not simply victims, however. They engage in a range of strategies to minimise negative impacts and they adopt several survival strategies to respond to environmental conflicts. These range from outright protestation (which can take the form of violent confrontation), through covert acts of resistance, to cooperation (which entails contestation and bargaining between actors with 


\section{Edwin C. Perry, Cheryl Potgieter and Urmilla Bob}

differential access to economic, political and social power and environmental resources). This relationship can vary in form, content and the arenas within which it takes place. The content depends on a spectrum of economic, social or political rules, practices and institutions. The arenas within which it takes place can be the household, the community and the state levels. These arenas can either reinforce or weaken each other's impact.

There are several examples of women organising to protest against environmental degradation. For example, the Green Belt Movement in Kenya is a well known organisation established by 2004's Nobel Peace Prize winner Wangari Maathai. The organisation was established in 1977 under the auspices of the National Council of Women in Kenya and organises poor women in Kenya to combat deforestation and environmental degradation. Another example is illustrated by Veuthey and Gerber (2009) who discuss women-led resistance movements to commercial logging in south-eastern Cameroon. The resistance arose because most of the socio-environmental costs of the international logging trade were imposed on rural populations and especially women in rural areas who rely on the forest resources for oil, medicine and other non-timber products.

Women adopt several coping strategies in response to real and perceived threats of violence during periods of environmental conflicts. Adopting a range of protective (intended to reduce or deter the risk of violence) and prevention strategies can play a major role in reducing women's vulnerability and increasing levels of security during periods of environmental conflicts. Some of these strategies include:

- Approaching government, especially at the local level, to increase policing/ law enforcement in the area where the conflict is taking place.

- Travelling in groups and staying together in refugee camps. The latter is an example of women moving out of an area to locations that are perceived to be safer.

- Creating defensible spaces such as installing security measures in their homes.

- Keeping away from particular people, places and situations that are deemed to be risky or dangerous, and avoiding individuals or institutions that do 


\section{Environmental conflicts and women's vulnerability in Africa}

not support the access of women to environmental resources. Avoidance is the most common strategy adopted by women although it results in several inconveniences to them.

- Seeking assistance and support from NGOs who set up refuges for women and children. In addition to the focus on the survivors of violence, many organisations arrange briefings and workshops for police and court officials to help them understand the significance of violence against females and enable them to deal more sensitively and justly with the cases that come before them.

- Negotiating and bargaining, which can include influencing negotiations and decisions behind the scenes by recruiting relatives of the chief and powerful men and women in the community or by persuading males to arbitrate on their behalf.

Women also adopt strategies of control and deception. Strategies of control involve women assuming personal control over environmental resources or specific spaces. Strategies of deception can take the form of deceiving decisionmakers about personal circumstances such as marital status. It can also include the manipulation of men in authority, especially those who control access to, and allocation and distribution of environmental resources.

Bogale et al. (2006:138) highlight the importance of women's participation in forums created to involve local stakeholders affected by resource conflicts in Ethiopia, and Wijeyaratne (2009:34) underscores the importance of women's participation in peace keeping processes in general, drawing from research undertaken in the Democratic Republic of the Congo and Uganda. Bogale et al. (2006:138) specifically show how participatory research methods can be used to permit participants to visualise complex issues through the use of simple techniques. This approach also allowed resource governance issues to be passed to local institutions such as youth groups and women's associations. However, it is important to note that several local organisations are generally not accessible to women and tend to be dominated by men. Wijeyaratne (2009:34) states that in broader based peace negotiation processes, 'when women do manage to get to the negotiating table, they are often confronted with the challenges of being 


\section{Edwin C. Perry, Cheryl Potgieter and Urmilla Bob}

included on equal standing with male counterparts, and of including substantive women's rights and gender equality provisions into agreements'. Pillay (2009:9) supports this position and states that in the Liberian peace processes in 2003 women were generally excluded from the formal peace talks and only a select few participated as observers despite their activism. Thus, women's presence is not the only issue. More important is making certain that there are spaces created and resources allocated to ensure effective and meaningful participation of women.

\section{Conclusion}

There is a need to develop gender-sensitive conceptual frameworks and methodologies that specifically focus on women and violence in relation to environmental conflicts. A multi-conceptual and interdisciplinary framework examines the spatial, economic, social and political dimensions. Furthermore, policy considerations for addressing gender issues relating to environmental conflicts need to be considered and should include recognising that environmental conflicts and the violence associated with these types of conflict are not gender neutral. It is clear that females experience a more heightened and widespread fear of violence and vulnerability associated with environmental conflicts that constrains their mobility, livelihood strategies and opportunities as well as level of participation in peace-keeping and decision-making processes.

Focusing on the importance of women and environmental conflicts underscores the role of women as environmental resource managers, their vulnerability to restricted and limited resource availability, and the need to develop environmental programmes aimed at assisting women. This article demonstrates that poverty and gender dynamics are central to understanding environmental conflicts and that these are particularly devastating for Africa's poor women. 


\section{Environmental conflicts and women's vulnerability in Africa}

\section{Sources}

Agarwal, B. 1996. A field of one's own: Gender and land rights in South Asia. Cambridge, Cambridge University Press.

Barnett, J. and W.N. Adger 2007. Climate change, human security and violent conflict. Political Geography, 26, pp. 639-655.

Bennett, E., A. Neiland, E. Anang, P. Bannerman, A. Aiq Rahman, S. Huq, S. Bhuiya, M. Day, M. Fulford-Gradiner and W. Clerveaux 2001. Towards a better understanding of conflict management in tropical fisheries: Evidence from Ghana, Bangladesh and the Caribbean. Marine Policy, 25, pp. 365-376.

Bogale, A., M. Taeb and M. Endo 2006. Land ownership and conflicts over the use of resources: Implication for household vulnerability in eastern Ethiopia. Ecological Economics, 58, pp. $134-145$.

Brocklesby, M.A. and E. Hinshelwood 2001. Poverty and the environment: What the poor say: An assessment of poverty-environment linkages in participatory poverty assessments. Swansea, UK, Centre for Development Studies, University of Wales.

Chambers, R. and G. Conway 1992. Sustainable rural livelihoods: Practical concepts for the $21^{\text {st }}$ century. Institute of Development Studies Discussion Paper No. 296. Sussex, Institute of Development Studies.

Cross, C. and D. Hornby 2002. Opportunities and obstacles to women's land access in South Africa: A research report for the Promoting Women's Access to Land Programme. Johannesburg, the National Land Committee and the Department of Land Affairs, in association with the Centre for Rural Legal Studies and the Centre for Applied Legal Studies at the University of the Witwatersrand..

Dasgupta, S., U. Deichmann, C. Meisner and D. Wheeler 2005. Where is the povertyenvironment nexus? Evidence from Cambodia, Lao PDR and Vietnam. World Development, 33 (4), pp. 617-638.

Frank, C. 2005. Costing crime: What value is there for policy making? SA Crime Quarterly, 11, pp. 33-36.

Fred-Mensah, B.K. 2003. Looking up to the victims: Land scarcity and women's role in food provisioning in the Ghana-Togo Border Area. Research Review, 19 (2), pp. 35-48.

Garcia-Moreno, C. 1998. Gender-based violence: An impediment to sexual and reproductive health. London, International Planned Parenthood Federation.

Kuo, F.E. and W.C. Sullivan 2001. Aggression and violence in the inner city: Effects of environment via mental fatigue. Environment and Behaviour, 33 (4), pp. 543-571.

Linn, E., N. Stein, J. Young and S. David 1996. Bitter lessons for all. In: Siegel, D. L. ed. Sexual harassment: Research and resources. New York, The National Council for Research on Women.

Mackenzie, M. 2009. The international politics of rape, sex and the family in Sierra Leone. Institute for Security Studies Paper 203. Available from: <http://www.issafrica.org/ uploads/P203.PDF> [Accessed 24 February 2010]. 


\section{Edwin C. Perry, Cheryl Potgieter and Urmilla Bob}

Mkhabela, T. 2006. Impact of land tenure systems on land conflicts: Swaziland - a country case study. Africanus, 36 (1), pp. 58-74.

Morrell, R. 2002. A calm after the storm? Beyond schooling as violence. Educational Review, 54 (1), pp. 37-46.

Nadesan, K. 2000. Victims of violence: An Asian scenario. Journal of Forensic Medicine, 7, pp. 192-200.

Ogra, M.V. 2008. Human-wildlife conflict and gender in protected area borderlands: A case study of the costs, perceptions, and vulnerabilities from Uttarakhand (Uttaranchal), India. Geoforum, 39, pp. 1408-1422.

Pain, R.H. 1991. Space, sexual violence and social control: Integrating geographical and feminist analyses of women's fear of crime. Progress in Human Geography, 15 (4), pp. 417-431.

Perry, E.C. 2002. Females' environmental perceptions of violence and danger in secondary schools: Case studies from the Durban Metropolitan Area, M.A. dissertation submitted to the Environment and Development Programme, University of Durban-Westville, Durban.

Pillay, A. 2009. Truth seeking and gender: The Liberian experience. African Journal on Conflict Resolution, 9 (2), pp. 91-99.

Rao, N. 2006. Land rights, gender inequality and household food security: Exploring the conceptual links in the case of India. Food Policy, 31 (2), pp. 180-193.

Rude, D. 1999. Reasonable men and provocative women: An analysis of gendered domestic homicide in Zambia. Journal of Southern African Studies, 25 (1), pp. 7-27.

Simiyu, R.R. 2008. Militarisation of resource conflicts: The case of land-based conflict in the Mount Elgon region of Western Kenya. Monograph 152, Institute for Security Studies, Pretoria.

Smiley, M. and A.D. Roux 2005. Measuring sources of stress in the environment, Research Network on Socio-economic Status and Health, John D. and Catherine T. MacArthur Foundation, Washington, DC. Available from: <http://www.macses.ucsf.edu/research/Social\%20 Environment/notebook/stress\%20survey.htm> [Accessed 4 December 2006].

United Nations 1995. Platform for Action and the Beijing Declaration, Fourth World Conference on Women, Beijing, China. New York, United Nations.

Veuthey, S. and J. Gerber 2009. Logging conflicts in Southern Cameroon: A feminist ecological economics perspective. Ecological Economics. Article in press.

Wijeyaratne, W. 2009. Women in peace processes: Lessons from the Democratic Republic of the Congo and Uganda. Conflict Trends, 3, pp. 34-41.

World Health Organisation 2002. World Report on Violence and Health. Geneva, World Health Organisation. 